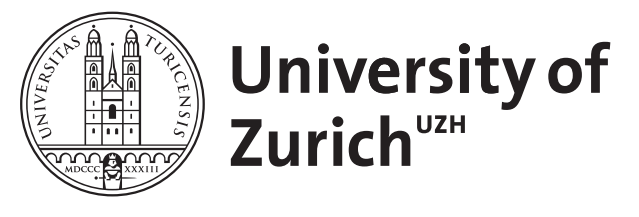

\title{
Local transportation policy and the environment
}

\author{
Schmutzler, Armin
}

\begin{abstract}
The paper introduces a simple framework for analyzing the environmental effects of local transportation policies, and it reviews some evidence. In several cases, subsidies for local public transportation have led to substantial reductions in road transportation and have thereby reduced externalities. Some but not all estimates suggest positive overall welfare effects of such policies. In the rare cases where road pricing has been applied, it has helped to reduce automobile transportation, and it has led to environmental improvements. The experience with specific driving restrictions like "days without cars" and "low emission zones" has been mixed. Local transportation policy can have a useful role to play as a complement to national policy instruments, but neither efficiency nor effectiveness can be taken for granted.
\end{abstract}

DOI: https://doi.org/10.1007/s10640-010-9447-5

Posted at the Zurich Open Repository and Archive, University of Zurich ZORA URL: https://doi.org/10.5167/uzh-51084

Journal Article

Originally published at:

Schmutzler, Armin (2011). Local transportation policy and the environment. Environmental and Resource Economics, 48(3):511-535.

DOI: https://doi.org/10.1007/s10640-010-9447-5 


\title{
Local Transportation Policy and the Environment
}

\author{
Armin Schmutzler*
}

Abstract: The paper introduces a simple framework for analyzing the environmental effects of local transportation policies, and it reviews some evidence. In several cases, subsidies for local public transportion have led to substantial reductions in road transportation and have thereby reduced externalities. Some but not all estimates suggest positive overall welfare effects of such policies. In the rare cases where road pricing has been applied, it has helped to reduce automobile transportation, and it has led to environmental improvements. The experience with specific driving restrictions like "days without cars" and "low emission zones" has been mixed. Local transportation policy can have a useful role to play as a complement to national policy instruments, but neither efficiency nor effectiveness can be taken for granted.

Keywords: Pollution, transportation, road pricing, public transport subsidies, driving restrictions

JEL codes: Q53, R41

*SOI, University of Zurich, Blümlisalpstrasse. 10, 8006 Zurich, Switzerland, CEPR, CIE, ENCORE, armin.schmutzler@uzh.ch. I am grateful to Adrian Müller, Max Pfister and an anonymous referee for helpful comments. 


\section{Introduction}

Road transportation is responsible for a large share of local and global air pollution, and it is associated with other problems such as congestion and accidents. Policy makers all over the world have attempted to deal with this issue. On the one hand, they have introduced nationwide measures like fuel economy standards, emissions norms or gasoline taxes. On the other hand, there are also many policies that address the externalities locally. Cities all over the world, from emerging market metropolises to medieval European towns, use driving restrictions to control road transport. Many European towns have recently introduced Low Emission Zones to reduce the ambient concentration of particulate matters (PM 10). Local public transport receives heavy subsidies in many regions, often motivated by environmental considerations. Road pricing schemes are discussed in many countries, and in some cases actually applied.

In the following, I will deal with such measures that are designed to alleviate transportation externalities at a local level. Introducing such instruments rather than working with national or even international policies can be justified when there are local pollution hot spots. In principle, the transmission mechanisms by which local policy instruments influence welfare are analogous to those of policy instruments that are implemented at a national level:

1. The policy instruments influence transportation patterns (level of transportation, modal split, composition of vehicles, traffic flows).

2. The changes in transportation patterns affect emissions.

3. The emissions influence ambient pollution levels.

4. Pollution adversely affects human health or more generally the quality of the services provided by the environment.

5. These quality changes correspond to welfare effects. 
In a narrow sense, economic analysis only deals with the first and last issue: It investigates how policy affects behavior, and it evaluates the welfare losses from pollution. The other issues are the domain of engineers, natural scientists and medical scholars. However, the boundaries between the different fields are becoming blurred. For instance, economic analysis can help to uncover the effects of policy instruments on ambient pollution levels (Section 3.3) or on health (see Section 5.2).

This review will therefore ask: What are the effects of local transportation policy instruments on pollution, health and welfare? I will mostly focus on evidence rather than theory. I will pay specific attention to those effects that are particularly relevant to local policy instruments. First, such instruments may improve the environmental quality in one region at the cost of higher pollution elsewhere. This concern is particularly obvious for bypass roads, but it also arises for road pricing and for driving restrictions such as low emission zones or pedestrian areas. The critical issue is the size of these undesired side effects. Can they be so large that they make up for the gains in environmental quality in the target area? Second, there could in principle also be positive effects on other regions. For instance, attractive public transport in a city can induce commuters from nearby regions to switch modes. Also, even measures that are primarily designed to reduce local transportation can contribute to reductions in global pollution: If such local measures lead to an overall reduction in driving, they will, other things equal, reduce carbon dioxide emissions even if this is not the prime intent of the measure.

The selection of papers included in this survey is, of course, to some extent subjective. Apart from the thematic restriction to policies that target small regions, several other points were important. First, I confined myself mainly to studies that capture the quantitative effects of policies on the basis of an ex-post assessment (rather than through ex-ante analysis, e.g., via simulations). Second, I gave preferential treatment to studies that provide a solid econometric assessment of the effects wherever available. I occasionally added anecdotal evidence, references to case studies, government reports, etc. 
when I could not find any superior sources.

The obvious problem of the following treatment is that it only deals with a very small fraction of the local transportation policies that have been introduced all over the world, mainly because not many of these policies have been investigated systematically. I will therefore put particular emphasis on the extent to which the conclusions from the small set of cases considered can be generalized, and I will highlight the limitations of such generalizability.

In Section 2, I introduce the framework for the analysis. Section 3 deals with the effects of supporting local public transport. In Section 4, I review some studies on driving restrictions. Section 5 reports on the limited experience with road pricing. Section 6 concludes.

\section{The framework}

In this section, I provide a formal framework that serves several purposes. First and foremost, it helps to define the issue of this survey more precisely. Second, it is useful to organize the literature. The issues treated below can be addressed within the framework, in some cases after mild modifications. Third, the framework allows us to identify through which channels the policy instruments under consideration might affect the allocation and, in particular, the emissions. Finally, the framework is useful for finding potential sources of inefficiency.

Because the framework is supposed to be applicable to a wide variety of related policy instruments, it seems most appropriate to take a reduced-form approach rather than to introduce a fully specified model that is explicitly based on maximization behavior. At least for the purpose of defining the issue and organizing the literature nothing is lost by this approach. Nevertheless, in the appendix I sketch one of the many conceivable models that can be used to provide a microfoundation for the reduced-form approach of this section. It helps to sharpen the understanding of the policy transmission channels, and of the sources of inefficiency. 
There are two regions, $r=1,2$. In region 1 , a local transportation policy $\theta$ is introduced. We treat $\theta$ as a parameter that affects transportation patterns and thereby emissions in an equilibrium model that we do not specify here. Also, for ease of exposition, I treat $\theta$ as a real variable in the following; but the framework can easily be adjusted to incorporate discrete instruments. The policy is designed to make car transportation in region 1 relatively less attractive than public transportation and/or reduce the environmental harm resulting from transportation. Region 2 summarizes neighboring areas in which no policy is introduced, but which may be indirectly affected by the policy.

For most of the discussion in the following, we distinguish only between two types of transportation, car transportation and public transportation. ${ }^{1}$ We denote the amount of car transportation in region $r$, measured in passenger kilometers, as $T_{r}^{C}(\theta)$. We capture the emissions from cars in region $r$ as $E_{r}^{C}(\theta) .{ }^{2}$ We introduce the notation $\eta_{r}^{C}(\theta)=E_{r}^{C}(\theta) / T_{r}^{C}(\theta)$ for the specific emissions from car transportation. We suppose that there is an alternative mode of transportation ("public transport"), and we denote the level of public transport in region $r$, measured in passenger kilometers, as $T_{r}^{P}(\theta)$, the emissions as $E_{r}^{P}(\theta)$ and the specific emissions as $\eta_{r}^{P}(\theta)=E_{r}^{P}(\theta) / T_{r}^{P}(\theta)$. Finally, we suppose that there are other economic activities (consumption and production) in each region, which are summarized in a vector $Y_{r}(\theta)$. We denote the emissions from these activities as $E_{r}^{Y}(\theta)$. Most of the empirical literature treated below does not explicitly treat possible effects of the policies on these other activities, that is, implicitly treats these other activities $E_{r}^{Y}$ as independent of $\theta$. This is obviously a simplification: For instance, a policy that makes local road transportation more expensive is likely to have substitution and income effects that influence the consumption of other goods (and thereby emissions); it will also tend to increase the costs of supplying other goods locally. As another example, if local public transportation is fi-

\footnotetext{
${ }^{1}$ Refining the approach by allowing further modes is straightforward.

${ }^{2}$ The formulation incorporates the case of heterogeneous emissions if $E_{r}^{C}(\theta)$ is regarded as a vector.
} 
nanced locally by taxes, it may crowd out other consumption and production activities, which again will influence emissions.

In this simple setting, total emissions in region $r$ are

$$
E_{r}(\theta)=T_{r}^{C}(\theta) \eta_{r}^{C}(\theta)+T_{r}^{P}(\theta) \eta_{r}^{P}(\theta)+E_{r}^{Y}(\theta) .
$$

Thus, the total effect of a marginal policy change on emissions in region $r$ is

$$
\frac{d E_{r}}{d \theta}=\frac{d T_{r}^{C}}{d \theta} \eta_{r}^{C}+\frac{d \eta_{r}^{C}}{d \theta} T_{r}^{C}+\frac{d T_{r}^{P}}{d \theta} \eta_{r}^{P}+\frac{d \eta_{r}^{P}}{d \theta} T_{r}^{P}+\frac{d E_{r}^{Y}}{d \theta} .
$$

Policy potentially affects emissions via five channels: The first term captures effects that result from changes in the amount of car transportation; the second term the effects on the specific emissions of car transportation. The third and fourth term are the corresponding expressions for public transportation. The last term, which I shall mostly ignore in the following, summarizes all the effects on non-transportation emissions.

The policy measures we consider are all supposed to reduce emissions by reducing the amount of car transportation in region $r=1\left(\frac{d T_{1}^{C}}{d \theta}<0\right)$ and/or the specific emissions of car transportation $\left(\frac{d \eta_{1}^{C}}{d \theta}<0\right)$. Reductions in the amount of car transportation will often go hand in hand with increases in public transportation $\left(\frac{d T_{1}^{P}}{d \theta}>0\right)$, either because the policy consists of a direct support of public transportation or because it makes driving cars less attractive and cars substitute towards public transportation. Either way, potential increases in public transportation may well lead to increases in pollution that counteract the targeted emissions reduction; this effect is captured by the term $\frac{d T_{1}^{P}}{d \theta} \eta_{1}^{P}$. In principle, the policy could also affect the specific emissions of public transportation, for instance, because increased patronage increases the load factor. This effect is captured in the term $\frac{d \eta_{1}^{P}}{d \theta} T_{1}^{P}$.

Equation (1) is useful for identifying some of the questions we shall deal with in the following. Very generally, the studies we consider aim at measuring the marginal effect $\frac{d E_{r}}{d \theta}$ of particular policies on the emissions 
in regions $r=1,2$. Often they focus on the immediate effect on emissions from car transportation, asking in particular what the combined effect $\frac{d E_{r}^{C}}{d \theta}=\frac{d T_{r}^{C}}{d \theta} \eta_{r}^{C}+\frac{d \eta_{r}^{C}}{d \theta} T_{r}^{C}$ on road transportation emissions is and, in particular, whether it is negative as desired. Even if $\frac{d E_{r}^{C}}{d \theta}<0$, these reductions in emissions could in principle be compensated by emissions from other modes of transportation. Therefore, it is also important to understand the relative size of $\frac{d E_{r}^{P}}{d \theta}$ and $\left|\frac{d E_{r}^{C}}{d \theta}\right|$.

Several papers deal not only with the intended policy effects on region 1, but also with potential adverse effects on region 2. For instance, even if a policy reduces car transportation in the particular region, and therefore satisfies $\frac{d E_{1}^{C}}{d \theta}<0$ as intended, it is possible that this effect comes at the cost of substitution of trips into other regions that are not targeted by the policy, resulting in higher emissions in these regions $\left(\frac{d E_{2}^{C}}{d \theta}>0\right)$. The possibility of such effects will be discussed, for instance, in the context of road pricing and low emission zones.

Though I will focus on the effects of the policy measures on emissions, some of the studies under consideration also deal with welfare effects more generally. We capture the adverse effects of emissions on welfare in a damage function $D\left(E_{1}, E_{2}\right)$, which is increasing in both arguments. As a crude simplification, we summarize the remaining welfare effects in an aggregate function $S\left(T_{1}^{C}, T_{2}^{C}, T_{1}^{P}, T_{2}^{P}, \eta_{1}^{C}, \eta_{2}^{C}, \eta_{1}^{P}, \eta_{2}^{P}\right)$; though some of the studies discussed below go beyond this simple form. ${ }^{3}$ First, the function captures effects on consumer surplus. All types of transportation increase consumer surplus. In principle consumer surplus can also be influenced by specific emissions from transportation (for instance, if low specific emissions are brought about by high load factors). Second, producer surplus can depend on all variables.

The net welfare is thus given as

$$
S\left(T_{1}^{C}, T_{2}^{C}, T_{1}^{P}, T_{2}^{P}, \eta_{1}^{C}, \eta_{2}^{C}, \eta_{1}^{P}, \eta_{2}^{P}\right)-D\left(E_{1}, E_{2}\right)
$$

\footnotetext{
${ }^{3}$ We thus abstract from policy effects on the surplus resulting from non-transportation activities.
} 
The total effect of policy on net welfare is thus

$$
\frac{d W}{d \theta}=\sum_{r=1,2}\left(\frac{d S}{d T_{r}^{C}} \frac{d T_{r}^{C}}{d \theta}+\frac{d S}{d T_{r}^{P}} \frac{d T_{r}^{P}}{d \theta}+\frac{d S}{d \eta_{r}^{C}} \frac{d \eta_{r}^{C}}{d \theta}+\frac{d S}{d \eta_{r}^{P}} \frac{d \eta_{r}^{P}}{d \theta}-\frac{\partial D}{\partial E_{r}} \frac{d E_{r}}{d \theta}\right)
$$

where $\frac{d E_{r}}{d \theta}$ is given by (1). The first term reflects the surplus effects of car transportation. The second term captures the effects of changes in the specific emissions of cars on the surplus; the third term is the corresponding term for public transport. The fourth term consists of the effects of increased public transportation. The last term contains the damages from increased emissions.

Assuming that the standard regularity conditions hold, an allocation $\left(\eta_{1}^{C}, \eta_{2}^{C}, \eta_{1}^{P}, \eta_{2}^{P}, T_{1}^{C}, T_{2}^{C}, T_{1}^{P}, T_{2}^{P}\right)$ is optimal if it satisfies the system of firstorder conditions. Without writing these conditions down explicitly, it is intuitive to see why they might be violated:

1. Emissions might be too low or too high;

2. the distribution of emissions across regions may be inappropriate;

3. emission reductions in each region might be achieved by an inappropriate mix of transportation reductions and reductions of specific emissions;

4. the mix of transportation (cars vs. public transportation) might be inappropriate;

5. the allocation might focus excessively on reducing the specific emissions from cars (relative to public transport) or vice versa.

In view of the simplicity of the framework, it is clear that it does not capture all sources of inefficiency that policy needs to be concerned with. To name only one example, if consumer heterogeneity was taken into account, the allocation could put excessive weight on pollution reductions of subjects for whom such reductions are particularly costly. 


\section{Public transport subsidies}

It is often assumed that the adverse effects of buses and railways on the environment are small compared to those of automobiles. Therefore most industrialized countries provide financial support for local public transportation, resulting in higher service quality or lower fares. Section 3.1 uses the general framework introduced in Section 2 to identify the sources determining whether support for public transport has beneficial environmental effects and to obtain a first rough idea of the likely size of such effects. Using (1), this depends on the answers to the following questions:

1. How much additional ridership do the measures generate, that is, how large is $\frac{d T_{1}^{P}}{d \theta}$ ?

2. To which extent does the increase in ridership reflect a reduction of car transportation, that is, what is the ratio $\left|\frac{d T_{1}^{C}}{d \theta}\right| / \frac{d T_{1}^{P}}{d \theta}$ ?

3. How do the specific emissions of public transport $\left(\eta_{1}^{P}\right)$ and cars $\left(\eta_{1}^{C}\right)$ compare?

4. How does the policy affect specific emissions; that is, what is the size of $\frac{d \eta_{1}^{P}}{d \theta}$ and $\frac{d \eta_{1}^{C}}{d \theta} ?^{4}$

Of course, a full welfare analysis would have to take additional effects into account (see equation (3)); but, except in Section 3.4, our focus will be on the environmental effects.

Some studies answer only one of the above questions at a time; others implicitly address several or even all of them simultaneously. In Section 3.2 , I will deal only with the effects of policies on transportation patterns (Questions 1 and 2) rather than the induced environmental effects. I will report on case study evidence and on attempts to come up with elasticities of

\footnotetext{
${ }^{4}$ The last question might appear irrelevant, as support for public transport does not directly target specific emissions. However, by influencing load factors, the policy may well affect emissions per passenger kilometer.
} 
public transport ridership and road transportation with respect to fares and the quality of service. Section 3.3 discusses papers that directly estimate the effects of transportation policies on pollution, thus addressing the first three questions together. Finally, Section 3.4 goes beyond the analysis of the pure emissions effects, by taking more general welfare effects into consideration.

\subsection{The potential for emissions reduction}

Before presenting results from empirical studies, I will use the general framework to obtain some rough quantitative ideas about the potential of public transport policies to reduce emissions $\left(\frac{d E_{1}}{d \theta}\right)$ and about the determinants of the size of the effect.

\subsubsection{The framework}

I will drop regional indices for simplicity. The transportation levels before the introduction of a policy are $T_{0}^{C}$ and $T_{0}^{P}$. The changes induced by the policies are $\Delta T^{C}$ and $\Delta T^{P}$, respectively.

Consider a policy (fare reduction, service improvement) which induces a growth of railway transportation by a fraction

$$
\tau^{P} \equiv \frac{\frac{\Delta T^{P}}{\Delta \theta}}{T_{0}^{P}} .
$$

Existing studies estimate such growth rates. ${ }^{5}$ Define

$$
\sigma \equiv \frac{\Delta T^{P}}{\Delta T^{C}}
$$

as the share of the increase in public transport that comes from a reduction in car transportation. ${ }^{6}$ Capture the relative importance of cars and

\footnotetext{
${ }^{5}$ These studies suggest that service elasticities should be around 0.5 for buses and somewhat higher for railways, whereas fare elasticities are around -0.3 (see Section 3.2.2).

${ }^{6}$ The results in Section 3.2.2 suggest a value around 0.6 for railways, but somewhat lower and more variable values for buses.
} 
public transport by

$$
\gamma \equiv \frac{T_{0}^{C}}{T_{0}^{P}}
$$

As a drastic simplification, suppose not only $E_{Y}$, but also $\eta_{C}$ and $\eta_{P}$ are constant. To capture the relative importance of transport emissions, let

$$
\theta \equiv \frac{E_{T}}{E_{Y}}
$$

The percentage growth rate of total emissions can easily be calculated as

$$
\rho=100\left(\frac{\eta^{C}\left(1+\frac{-\sigma \tau^{P}}{\gamma}\right) \gamma+\eta^{P}\left(1+\tau^{P}\right)+\frac{\eta^{C} \gamma+\eta^{P}}{\theta}}{\eta^{C} \gamma+\eta^{P}+\frac{\eta^{C} \gamma+\eta^{P}}{\theta}}-1\right)
$$

The following illustrations help to understand how the parameter values influence the potential for emissions reduction. First normalize $\eta_{C}=1$. Let $\sigma=0.5$ and $\gamma=9$; that is, $50 \%$ of the increase in public transport comes from reductions in car transportation, and cars are responsible for $90 \%$ of local transportation. Consider the effects of a $10 \%$ growth in public transportation.

Figure 1 gives the percentage change of total emissions as a function of the importance of transportation emissions $(\theta)$ under different assumptions on the specific emissions $\eta^{P}$. When there are no emissions from public transport $\left(\eta^{P}=\eta^{P}=0\right)$, the maximal reduction of total emissions (when emissions come exclusively from transportation) is slightly above $0.55 \%$ : Because railways only account for a small share of total transportation, total emissions are hardly affected even by a substantial increase in public transport. If railways themselves pollute, then the potential reduction is smaller; and it will be exactly zero for all $\theta$ when $\eta^{P}=\eta^{P}=0.5$, that is, public transport pollutes half as much as cars per passenger kilometer. This reflects the assumption that only $50 \%$ of the increase in rail travel come from reductions in car transportation: When only a part of the increase in public transportation comes from reduced car ridership, lower specific emissions of railways do not suffice to guarantee positive environmental effects of public transport. 


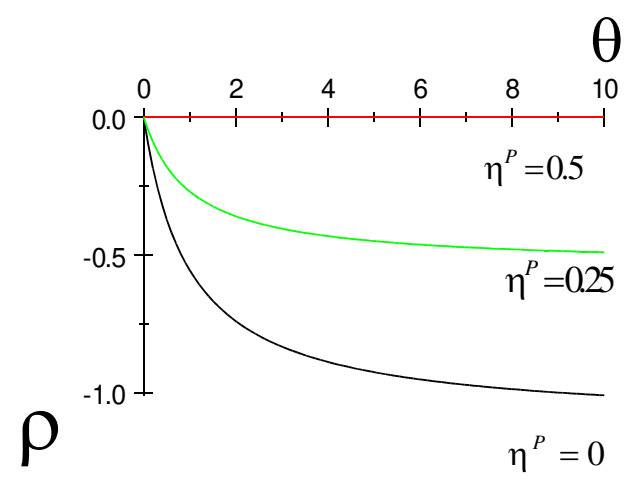

Figure 1: Emissions Reduction Potential from Public Transport (Role of Share of Transportation Emissions)

Figure 2 gives the percentage reduction of total emissions as a function of the relative importance of car transportation $(\gamma)$ under different assumptions on the specific emissions from rail transportation. ${ }^{7}$ The potential emissions reduction is decreasing in $\gamma$. Suppose railways do not contribute to pollution at all $\left(\eta_{0}^{P}=\eta_{1}^{P}=0\right)$. In the relatively optimistic case that public transport is initially responsible for one third of total transportation $(\gamma=2)$ a further increase of rail transportation by $10 \%$ would reduce total emissions by $1.25 \%{ }^{8}$ For more common values $(\gamma \geq 5)$, the change would be $0.5 \%$ or less.

\footnotetext{
${ }^{7} \eta_{0}^{P}=\eta_{1}^{P}$ are taken to be $0,0.25,0.5$ as before. The remaining parameters are fixed as before, except that the share of the initial emission share of the transportation sector is now fixed at $50 \%$, so that $\theta=1$.

${ }^{8}$ For instance, the value $\gamma=2$ corresponds to the situation in the canton of Zurich in 2005, which has an unusually dense public transport network. The shares are $60 \%$ for cars, $29 \%$ for public transport; the rest is bicycle and pedestrian traffic:

$<\mathrm{http}: / /$ www.statistik.zh.ch/themenportal/themen/aktuell_detail.php?id=4638\&tb=1\&mt=7>; April 2, 2010.
} 


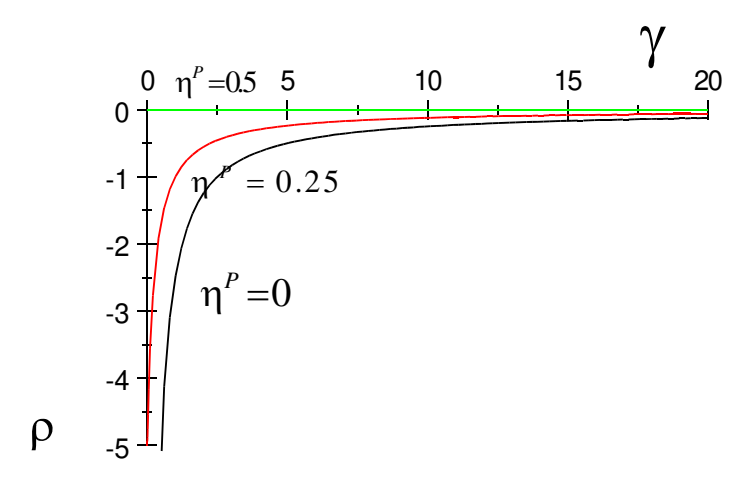

Figure 2: Emissions Reduction Potential from Public Transport (Role of Importance of Public Transport)

\subsubsection{Summary and Discussion}

This section identifies determinants of the potential for reducing emissions by supporting public transport, such as the initial modal split, the overall share of transportation, and the degree of substitution and the relative specific emissions. It also suggests that under realistic assumptions, the effect of supporting puiblic transportation might not be very large.

I will now review empirical evidence on some of the variables identified here.

\subsection{Effects on Ridership}

A necessary condition for the mechanism just sketched to be effective is that the policy measures under consideration are successful in increasing public transport in the target region, that is, that $\frac{d Y_{1}}{d \theta}$ is sufficiently large. The existing evidence on this topic is mainly anecdotal, with only crude attempts for quantification and causal inference. 


\subsubsection{Cases}

Several papers provide accounts of unusual growth of public transport in specific cities which they attribute to policy measures. For instance, Fitzroy and Smith (1998) deal with the development of public transportation in the German city of Freiburg. Between 1983 and 1995, the number of public transport trips rose from 27.7 to 65.9 million trips per year, after a long period of stagnation. This development was reflected in an unusual increase in the share of public transport rose from $11 \%$ in 1982 to $18 \%$ in 1992 . Understanding the determinants of this evolution is difficult, because public transport was supported in several different ways. The supply of buses and trams increased. A large-scale park-and-ride system was introduced. The fare system was changed, with a particular emphasis on "Environmental Cards", cheap season tickets for the entire network. In addition, various traffic restraints were introduced, such as pedestrian zones, low speed zones and parking charges. The authors provide a brief econometric analysis that accounts for some of these factors. However, they do not address all of them and, in particular, they do not consider possible interactions. Nevertheless, some tentative conclusions emerge from the analysis and the descriptive evidence. The authors argue that the cheap season tickets had an important effect on demand for public transportation. The introduction in 1984 accounted for an increase in ridership by $9 \%$ and the extension of the range in validity in 1991 was responsible for another $13 \%$. By comparison, the effect of the expanded tram system was small, with a service elasticity of $0.24 .^{9}$

\footnotetext{
${ }^{9}$ In a similar vein, Pucher and Kurth (1995) collect descriptive evidence from five local public transportation systems in Germany (Hamburg, Munich and the Rhein-Ruhr region), Switzerland (Zurich) and Austria (Vienna). In all these cities, an integrated transportation authority (Verkehrsverbund) was founded at some stage between 1967 and 1990, and transportation grew, in spite of an overall negative trend.
} 


\subsubsection{Elasticities}

Many studies analyze the effects of fare reductions and service levels on public transport ridership, so that it is impossible to do justice to the literature. The following very brief account serves the sole purpose of obtaining a very rough impression of the quantities involved.

Evans (2004) provides an account of half a century of evidence on the elasticities $\left(\frac{\Delta T_{1}^{P}}{\Delta \theta}\right) \cdot\left(\frac{\theta}{T_{1}^{P}}\right)$ of public transport ridership with respect to certain policy variables $\theta$. Though results for the United States dominate, the paper also deals with cases from other countries, including Canada, the U.K. and Norway. The underlying studies differ with respect to geographic and demographic factors and the pre-existing service and fare levels, the time of the measure and the adjustment time that was used to calculate the elasticities. Nevertheless, some useful insights emerge.

For buses, the average service elasticity is approximately $0.5 .{ }^{10}$ Elasticities above 1 are sometimes observed, but that is rare. As one might expect, the elasticities are higher when initial service levels are low. For railways, the elasticities are larger, with values between 0.5 and 0.9. ${ }^{11}$ Evans (2004) also compiles results on the effects of fare changes on bus transportation. He finds fare elasticities between -0.25 and -0.35 for San Diego and London. ${ }^{12}$

The motivation for public transport subsidies comes from the expected reductions in car ridership. Quite generally, the response of public transport to fares or service levels should be an upper bound for the absolute value of the induced response of car ridership, because only some of the new public transport users would otherwise use cars. Evans (2004) contains evidence for such mode shifts from experiments in the Boston area carried out in the

\footnotetext{
${ }^{10}$ These elasticities give the percentage change in ridership induced by a $1 \%$ change in the frequency of service.

${ }^{11} \mathrm{An}$ outlier is provided by a study of London Transport (1993) which reports very low service frequency elasticities of underground trains (0.08), which is below half the corresponding value for buses.

${ }^{12}$ Again, the elasticity for the Underground system is considerably lower than for buses in London.
} 
nineteen sixties. He reports that $64 \%$ of the riders attracted by increasing commuter rail frequency previously used their own car; $17 \%$ a carpool and $19 \%$ the bus. The figures for increases in bus ridership vary substantially, between 18 and $67 \%$. Pratt et al. (2000, 12-40ff.) report estimates between 60 and $80 \%$ for various U.S. cities.

\subsubsection{Summary and Discussion}

The studies summarized briefly in this subsection suggest that support for public transport may at least have the qualitative effects on transportation mentioned in Section 2, and they provide a rough idea of the relevant magnitudes. Several important issues remain open, however. First, in view of the heterogeneity of the observed elasticities, it would be desirable to improve the understanding of the determinants of the size of the effect. Many variables can potentially play a role, such as geographical characteristics of the region, the degree of motorization, income level and distribution, etc. To draw conclusions that are applicable beyond the regions under consideration, such factors must be taken into consideration. Second, the effects of policies on the environment have to be investigated more carefully. We now address this issue.

\subsection{The Effects on Pollution}

The above results provide incomplete evidence for the idea that supporting public transport may have beneficial environmental effects: Increased service frequency and fare reductions lead to higher ridership $\left(\frac{d T_{1}^{P}}{d \theta}>0\right)$ for these policies) and thereby to a reduction in road transportation $\left(\frac{d T_{1}^{C}}{d \theta}<0\right)$. Assuming that public transportation leads to sufficiently smaller externalities per passenger mile $\left(\eta_{1}^{C}<\eta_{1}^{P}\right)$ and that $\left|\frac{d T_{1}^{C}}{d \theta}\right|$ is sufficiently large relative to $\frac{d T_{1}^{P}}{d \theta}$, this substitution effect should then lead to lower pollution $\left(\frac{d E_{1}}{d \theta}<0\right)$. Justifying these assumptions is of course the missing link in the argument. An obvious way to proceed would be to come up with specific emissions of 
the different transportation modes $\left(\eta_{1}^{C}\right.$ and $\left.\eta_{1}^{P}\right)$ and to combine them with the previous estimates of the effects of policy on transportation behavior. ${ }^{13}$ Specific emissions obviously depend on many details. As an alternative to this approach, I will therefore present two recent studies that directly estimate the impact of improved local public transportation on pollution. These studies are useful not only because of the results presented for the specific cases, but also because they point to two approaches to obtaining clean estimations of environmental policy effects, namely exploiting either large-scale policy changes or inter-regional policy variation, that are applicable more generally.

\subsubsection{A new metropolitan transportation system}

Chen and Whalley (2010) provide a sophisticated empirical analysis of the effects of improved public transportation on local pollution, using evidence from Taipei, the capital of Taiwan. The analysis is interesting for several reasons. First, it provides a clean approach to analyzing the effects of public transportation on local air pollution that is potentially applicable elsewhere. Second, by focusing on a city in a rapidly growing emerging economy, it deals with a case where the scope for environmental quality improvements from public transportation is potentially large, because air pollution in the counterfactual scenario would increase rapidly and there is substantial growth potential for public transportation.

Identifying the effects of a new public transportation system on pollution is not a simple task. For instance, the simple-minded approach of regressing daily pollution levels on daily public transport ridership would most likely fail because of endogeneity problems: If exogenous circumstances drive up the demand for all types of transportation on certain days, one might well observe a positive correlation between high usage of public transportation and high pollution levels (because of increasing road transportation), without

\footnotetext{
${ }^{13} \mathrm{~A}$ recent example for the calculation of such specific emissions for cars and railways is IFEU (2010). Infras (2010) provides more detailed values for road transportation.
} 
there being any positive causal relationship between the two. To avoid such problems, the authors exploit a large exogenous variation in public transport ridership to identify its effect on carbon monoxide, nitrogen oxides and ozone. In 1996, a new Mass Transportation System was introduced in Taipei, which made public transport much more attractive than before. One would therefore expect a discrete jump in ridership, and this indeed occurred. ${ }^{14}$ To some extent, this increase should reflect lower car ridership. For pollutants such that trains have substantially lower emissions per passenger, therefore, emissions and ambient concentrations should fall.

To identify the effects of the discrete increase in the quality of public transportation, Chen and Whalley (2010) apply a regression discontinuity analysis, which isolates the discrete change from the time trend. They show that the new transportation system led to a significant drop in carbon monoxide emissions (by 9-14\%). For nitrogen oxide, the effects were similar, but only weakly significant. Unsurprisingly, there were no clear-cut effects on groundlevel ozone, which reflects the complexities of the chemistry of ozone. ${ }^{15}$ The authors also provide some results that lend credibility to their identifying assumption that, without the new transit system, air quality would not have changed discretely: They show that no similar improvements in air quality took place in other Taiwanese cities around the opening date, and they also showed that, in Taipei itself, the concentration of pollutants unrelated to transportation did not change in a discrete fashion either.

Using their causal analysis, the authors calculate the welfare gains from reductions in infant mortality as 260 Million US Dollars. They use this to argue that the figures applied elsewhere ${ }^{16}$ to value public transport subsidies understate their positive effect, at least when applied to developing country metropolises.

\footnotetext{
${ }^{14}$ From the very beginning, about 3 Million riders per month used the system.

${ }^{15}$ Though nitrous oxides are among the precursor substances of ozone, reductions in $N O_{x}$ emissions do not necessarily reduce ozone concentrations; the effect depends on the ratio between $N O_{x}$ and volatile organic compounds.

${ }^{16}$ See, e.g., Parry and Small 2009 (discussed in Section 3.4 below).
} 


\subsubsection{Large Scale Support for Regional Public Transport}

In the context of the railway reform of 1994, Germany set up a large-scale program to support local railway services. Apart from introducing the possibility of competitive tendering, the federal government has since then supplied around 5-6 billion Euros per year to the state governments to subsidize regional passenger transportation. These subsidies have led to substantial increases in the frequency of service. Again, theses measures are expected to increase ridership $\left(\frac{d T_{1}^{P}}{d \theta}>0\right)$ at the expense of car transportation $\left(\frac{d T_{1}^{C}}{d \theta}<0\right)$, leading to an overall reduction in emissions $\left(\frac{d E_{1}}{d \theta}<0\right)$. As the discussion in Section 3.1 has shown, this conclusion cannot be taken for granted.

Therefore, Lalive et al. (Work in Progress) match a detailed data set of 550 railway lines with a set of local pollution data to identify the environmental effects of public transportation subsidies. They use the fact that the regional variation in the expansion of public transportation has been considerable. The authors exploit this fact to identify the effects of improved public transport on local environmental quality and also on road accidents. They hypothesize that improved railway services should reduce automobile traffic and thereby lead to fewer road accidents and to lower overall pollution for carbon monoxide, nitrogen oxides and particulate matters. For these pollutants the specific emissions from road transportation are considerably higher than for rail, and transportation has a high share of overall emissions. However, there should be no effect for ozone (for which there is no clear positive relation between automobile emissions and concentration) and for sulfur dioxide, which is not strongly related to transportation at all. Preliminary results that use a suitable instrument to address the potential endogeneity of transportation improvements suggest that improved railway services indeed have the predicted effects. ${ }^{17}$ The results also suggest that, by reducing

\footnotetext{
${ }^{17}$ Building from the results of Lalive and Schmutzler (2008), they use the mode of procurement as an instrument (see Section 3.4) . They show that the frequency of railway services grows more strongly on competitively procured lines, but otherwise there seems to be little difference between competitive and non-competitive lines, except for variables
} 
automobile pollution, improved railway services lead to lower infant mortality. This is consistent with the results by Currie and Reed (2009) who show that reducing emissions by improving traffic flows can have positive effects on infant health (see Section 5.2).

In view of the sceptical remarks in Section 3.1, it may appear surprising that the effects of public transport policies on environmental quality appear to be quite substantial in Germany. To a large extent, the discrepancy can be explained by the sheer size of the increase in public transportation: The frequency of service on many German passenger railways grew substantially since the middle of the nineteen nineties. ${ }^{18}$ To my knowledge the effects of these changes on ridership have never been investigated analytically, but at least Allianz pro Schiene (2010) complies a list of 16 successful cases of seemingly moribund railway lines, most of which achieved increases in ridership by several multiples within a decade or less. In all of these cases, there were substantial increases in the frequency of services, but usually by a much smaller percentage than the resulting increase in ridership.

\subsubsection{Summary and Discussion}

The studies in this subsection identified clear effects of improved local transportation on several pollutants. Of course, these results were generated for specific examples, and there is no guarantee that they hold elsewhere. However, at least the design of the study by Lalive et al. indicates how more general insights might be achieved. Even though the authors focus on Germany, the data points concern hundreds of different regions with different characteristics. Potentially, therefore, this information can be used to identify the circumstances fostering beneficial environmental effects of public transportation, at least within the sample. Even though the external validity of the results cannot be taken for granted, they would at least provide a first step for informing policy outside of Germany.

that can be controlled for.

${ }^{18}$ Lalive and Schmutzler report a growth of approximately $28 \%$. 


\subsection{Welfare Effects}

Parry and Small (2009) introduce a general framework to empirically evaluate the welfare effects of subsidies, and they apply to specific cases.

\subsubsection{Framework and Applications}

This framework can be used to predict whether marginal reductions of existing fares would lead to higher welfare. The total welfare effect consists of four components, which are related to, but not identical with those identified in equation (3). The main differences are that the authors distinguish between different modes of public transportation, and that they allow for different quality levels for each mode. We can easily refine the approach of Section 2 by distinguishing between the modes $P^{1}$ (the mode that is being supported) and $P^{2}$ (the remaining modes), and by introducing different quality levels.

First, there is the marginal cost/price gap: Fare reductions increase ridership for the particular mode, which increases both consumer surplus and production costs; as the price is typically below marginal costs in the status quo, this effect tends to be negative. ${ }^{19}$ Second, there is the net scale economy effect, reflecting benefits for the customers from increases in service frequency and route density as well as losses from increasing vehicle occupancy. Third, there is an externality effect which consists of the increasing externalities for the particular mode of public transport and decreasing externalities from automobiles. ${ }^{20}$ Finally, the other transit term captures the effect of reductions in the ridership of other modes of public transport, namely reduced supply costs, but also reduced externalities. Also, users of these other modes benefit from reduced vehicle occupancy, but suffer from decreasing service frequency and route density. ${ }^{21}$

\footnotetext{
${ }^{19}$ Adapting the language of Section 3.1, this effect can be written as $\frac{d W_{r}}{d T_{r}^{P_{1}}} \frac{d T_{r}^{P_{1}}}{d \theta}$.

${ }^{20}$ In the (adjusted) terminology of Section 2, this corresponds to $\frac{d D_{r}}{d E_{r}}\left(\frac{d E_{r}^{C}}{d T_{r}^{C}} \frac{d T_{r}^{C}}{d \theta}+\frac{d E_{r}^{P_{1}}}{d T_{r}^{P}} \frac{d T_{r}^{P_{1}}}{d \theta}\right)$.

${ }^{21}$ These effects can be captured as $\frac{d W_{r}}{d T_{r}^{P_{2}}}$ and $\frac{d D_{r}}{d E_{r}}\left(\frac{d E_{r}^{P_{2}}}{d T_{r}^{P_{1}}} \frac{d T_{r}^{P_{2}}}{d \theta}\right)$.
} 
To apply the approach in a particular example, a long list of questions has to be answered: (i) To which extent does the agency respond to an increase in demand by expanding capacity rather than increasing vehicle occupancy? (ii) What are the average operating costs per vehicle mile and per passenger mile? (iii) What are the passenger fares? (iv) What are the user costs (waiting, crowding, access?) and the benefits and costs from scale economies? (v) What are the externalities from pollution and congestion? (vi) What are the relevant elasticities?

The authors apply their approach to the public transportation systems of London, Washington and Los Angeles. With only one exception (peakperiod buses in Washington), they find positive welfare effects of increasing the current subsidy. The size is around 0.2-0.6 cents per passenger mile onecent increase in the subsidy. The authors also compare their results to earlier studies. Perhaps unsurprisingly, these other studies arrive at widely varying conclusions. ${ }^{22}$

\subsubsection{Summary and discussion}

Parry and Small (2009) provide a convincing framework for analyzing the welfare effects of transportation subsidies, but there are at least two caveats. First, it is not clear that the underlying welfare function should be quasiconcave in fares. Thus, even if the approach allows to estimate the welfare effects of marginal changes in fares (and thus subsidies), it does not necessarily have much to say about the global optimum of the problem. On the one hand, even when small subsidy increases lead to higher welfare because they encourage higher ridership in an existing system, it might still be preferable

\footnotetext{
${ }^{22}$ Glaister and Lewis (1978) and Glaister (1984) came up with similar results for London. Studies of Chicago (Savage 1997) and some Australian cities (Dodgson 1986) support the case for lower fares. Winston and Shirley (1998) find low optimal subsidies, and, for the Washington rail system, Winston and Maheshri (2007) calculate a net welfare loss of USD 195 million per year. In the last two studies, the different conclusions can be traced to factors such as the different treatment of sunk capital costs and scale economies.
} 
to abolish the system altogether to save on the potentially large fixed costs. ${ }^{23}$ On the other hand, even when small subsidy increases do not have a positive effect on net welfare, very high increases can, in principle, lead to so much higher increases in ridership that they improve welfare compared with the status quo. While some of the results on elasticities discussed in Section 3.2.2 suggest otherwise, the anecdotal evidence from Germany reported in Section 3.3.2 indicates that such effects may be important.

Second, providing estimates of the relevant quantities is obviously subject to many problems. For instance, the externalities should include carbon dioxide as a global pollutant, diverse local pollutants, noise and congestion. Estimating the costs of each type of pollution is subject to large methodological problems and value judgments. For the case of carbon dioxide, this point has been belabored elsewhere, without any sign of a reliable consensus. Even for the comparatively simple case of local pollutants, the task is nontrivial. For instance, as the discussion in Section 5.2 will show, developing reliable estimates of the causal effects of local pollutants from transportation on health is a difficult task.

Contrary to other studies mentioned in this section, the paper by Parry and Small (2009) not only deals with individual cases, but provides a framework that is widely applicable to quantify the welfare effects of small policy changes. To exploit the potential of the paper further, it would be desirable, however, to address more different cases in this unified framework, so as to identify the circumstances fostering beneficial welfare effects. Parry and Small themselves allude to a special aspect of this point: They remark that the welfare effects will also depend on the organization of public transport, which in many cases appears to be inefficient, for instance, because competitive forces are rarely used. Lalive and Schmutzler $(2008,2010)$ provide some evidence in this direction. They exploit the fact that the German railway reform allows competitive tendering of regional passenger transport,

\footnotetext{
${ }^{23}$ However, a large part of the fixed cost may be sunk at the time the fare reductions are discussed.
} 
but does not force local agencies to use this tool. They show that the frequency of service has grown more strongly on railway lines where competitive tendering was used, suggesting that the required subsidies on these lines are lower, so that agencies can afford service expansion. This interpretation is also supported by further analysis that uses subsidy data directly (Lalive and Schmutzler, 2010). Subsidies are much lower on competitively procured lines than on otherwise comparable lines that are served by the former monopolist, Deutsche Bahn. Assuming as in Section 2 that there is a positive cost of public funds, competition therefore has desirable welfare effects by reducing the rents of suppliers.

\section{Driving restrictions}

An alternative approach to dealing with road-transportation related externalities consists of driving restrictions. Such restrictions can take many forms. Pedestrian zones or speed limits are obvious examples, but the studies we refer to in the following deal with more creative policies. These studies are useful, because they illustrate the potential pitfalls of the policy measures under consideration.

First, some large cities, in particular in Latin America, limit the number of weekdays on which any car is allowed to drive. This type of policy is supposed to reduce car ridership altogether $\left(\frac{d T_{1}^{C}}{d \theta}<0\right)$ and thereby curb pollution $\left(\frac{d E_{1}}{d \theta}<0\right)$. We deal with the effects in Section 4.1. Second, we consider the regulation of particulate matters in the EU, a policy that has led to the creation of so-called low emission zones that allow entry only for cars with suitable emissions properties (Section 4.2). This policy is supposed to reduce emissions both by reducing car transportation and by changing the composition of cars in the area in an environmentally benign way $\left(\frac{d \eta_{1}^{C}}{d \theta}<0\right)$. 


\subsection{Weekday restrictions}

Many large cities in Latin America attempt to reduce air pollution and congestion by restricting the number of weekdays on which any given car is allowed to drive in the city. For instance, in 1989 a scheme (Hoy no circula) was introduced in Mexico city, according to which each car is not allowed to drive on one particular day of the week between 5 a.m. and 10 p.m. There are some obvious costs and benefits of such a system. On the one hand, it is based on the number-plate of the car and is thus easy to monitor. On the other hand, it is hardly the most efficient approach to pollution reduction, as it potentially imposes high costs on drivers who need to travel on particular weekdays. What is more surprising, however, is that behavioral adaptations appear to have led to increases in the levels of various pollutants. This claim has been substantiated by the empirical analysis of Eskeland and Feyzioglu (1997), which has recently been refined by Davis (2008).

\subsubsection{Effects on Transportation}

Eskeland and Feyzioglu suggest mechanisms which might neutralize the expected reduction of pollution or even lead to an increase of pollution as a response to the regulation. First, some drivers may buy additional cars to avoid the day without a car. These additional cars might be cheaper and more polluting, so that there might be an undesired side-effect $\frac{d \eta_{1}^{C}}{d \theta}>0$. Second, families that buy a second car to avoid regulation are likely to drive more than with one car in the absence of regulation. Third, even households who do not buy additional cars might substitute some of their trips towards the night or the weekend. The two last effects suggest that it is not even clear that $\frac{d T_{1}^{C}}{d \theta}<0$. Using data from 1987 to 1992, the authors estimate the effect of the regulation by constructing a counterfactual argument. To do so, they estimate gasoline demand based on pre-regulation data. The results suggest that, without the regulation, demand would have been lower except in the two first quarters after the regulation. 


\subsubsection{Effects on Pollution}

Eskeland and Feyzioglu (1997) do not analyze the changes in local pollutants directly. Davis (2008) goes much further. He measures the effects of the regulation on five major local pollutants, ${ }^{24}$ using detailed data from monitoring stations for the years 1986 to 1993 . Of course, it would be desirable to use a comparable non-regulated city to construct a counterfactual, but the author argues quite credibly that Mexico city is so unique that it is hard to find a suitable candidate. Instead, he provides a careful before-and-after analysis. He keeps the time window relatively small so as to avoid confounding factors like the introduction of the strict U.S. emission standards in 1994. He also attempts to identify jumps in behavior at the point of introduction of the new law by using a regression discontinuity analysis similar to Chen and Whalley (2010).

In the main specification, he estimates the effect of the regulation on average hourly air pollution, using covariates such as the month of the year, day of the week or hour of the day as well as weather variables. He finds no negative effect of the program on average hourly emissions. On the weekends pollution increases, which is consistent with the idea that drivers shift from days with driving restrictions to non-regulated days. Nevertheless, not even the peak-level weekday emissions are reduced, for which regulation is most likely to have the expected negative effect on pollution. In fact, there is a discontinuous increase in the maximum daily air pollution levels. Davis (2008) also provides some evidence for the sources of change. Consistent with Eskeland and Feyzioglu (1997) he finds no sign of a reduction in gasoline consumption. Instead, he observes a decrease in public transport ridership and an increase in vehicle registration and sales.

\footnotetext{
${ }^{24} \mathrm{He}$ considers carbon monoxide, ozone, nitrogen oxides, nitogen dioxide and sulfur dioxide.
} 


\subsubsection{Summary and discussion}

The analysis of Hoy no circula invites an obvious conclusion. This specific type of driving restriction is not only potentially inefficient, it even seems to be ineffective, because it leads to countervailing behavioral adaptions. Nevertheless, the conclusion is merely that "Rationing can backfire". Precisely because of "the unique geography,..., unique transportation system, and unusually large population" (Davis 2008) of Mexico City, it is not entirely obvious what the analysis implies for cities such as Bogota, Santiago and Sao Paulo that have introduced similar programs. However, there are clearly reasons to be skeptical: Such measures target the environmental goal in an extremely indirect way. While monitoring costs can justify such an approach in principle, it appears that the flaws of the system dominate, and there is no obvious reason to believe it should perform better elsewhere.

\subsection{Low Emission Zones}

It is hard to think of any local pollutants that have recently received more attention than particulate matters. These substances cause a variety of cardiopulmonary illnesses, from acute respirotary diseases to lung cancer (EPA 2004). As a result, regulation of PM 10 and PM 2.5 has become increasingly stringent in recent years. ${ }^{25}$ We focus here on the EU regulation of PM 10, because this has led to the introduction of interesting policy measures with potential undesirable spatial size effects. ${ }^{26}$ This regulation has gone through several stages, but the main features are as follows:

1. The EU sets maximum ambient concentration levels.

2. Countries with communities that are not in compliance with the rules are fined.

\footnotetext{
${ }^{25}$ PM 10 and PM 2.5 refer to classes of particular matter, with PM 10 (2.5) consisting of all particulates with a diameter of 10 (2.5) micrometers or lower.

${ }^{26}$ The brief description of the institutional details is based on the more detailed treatment of Wolff and Perry (forthcoming).
} 
3. The details of how communities are induced to achieve attainment status are left to the national governments.

In Germany, for example, non-attainment areas have to develop "action plans" to alleviate the problem. As transportation is the main culprit for PM 10 pollution, these action plans typically target emissions of road vehicles by measures such as expansion of public transport, improvements of transportation flows and the utilization of ring roads. Of particular interest is the widespread use of so-called low emission zones. ${ }^{27}$ Only vehicles that have sufficiently low PM 10 emissions are allowed into these zones. The four emission categories are testified by easily visible windshield stickers. Drivers who do not comply are fined.

In principle, several responses of drivers are conceivable. Some of these responses should unambiguously lead to lower PM 10 emissions. For instance, drivers might use public transport $\left(\frac{d T_{1}^{P}}{d \theta}>0\right)$, upgrade their cars through retrofits or even drive new, less polluting cars $\left(\frac{d \eta_{1}^{C}}{d \theta}<0\right)$. Given the relatively high costs of these measures, however, it is also conceivable that drivers simply avoid the critical zones by driving around them. Thus the net effect of low emission zones on PM 10 pollution is unclear. Within the low emission zones, pollution should decrease, but emissions in the vicinity may well increase. Such motivated, Perry and Wolff (2009) have analyzed the effects of German low emission zones in more detail.

They not only investigate the effect $\frac{d E_{1}^{C}}{d \theta}$ for the targeted region; they also consider spatial substitution, that is, the effect $\frac{d E_{2}^{C}}{d \theta}$. They consider a panel of PM 10 levels in various German cities. They ask how the LEZs changed local emissions. They find that, within the zones, PM 10 levels have decreased by $9 \%$. Even in surrounding areas, the effect seems to go in the same direction, suggesting that spatial substitution is not a problem.

The authors also investigate the sources of the emission reduction. The closer drivers live to low emission zones, the more likely it is that they adopt

\footnotetext{
${ }^{27} 41$ of the 79 German cities that are violating PM 10 regulation, 34 have implemented such zones, and many others are considering their introduction.
} 
cleaner technologies. To judge the long-term effects of the policy, it would be interesting to understand the adoption behavior of drivers from surrounding neighborhoods. It is quite conceivable that they adopt cleaner technology only after an extended period of frustration with the driving restrictions or even when they buy a new car. Also, a full analysis of the environmental effects would also have to take adverse effects from the early scrapping of fully functional vehicles into account.

\subsubsection{Summary and Discussion}

Even though the paper of Perry and Wolff (2009) does not provide a full welfare analysis, it suggests that low emission zones can be effective at addressing specific pollution problems. Another potentially useful aspect of the empirical design that it can potentially help to provide information on the factors contributing to the success of such measures: Because many different cities are included, it should be possible to identify the circumstances fostering desirable emissions effects by including suitable controls.

\section{Road Pricing}

A famous article on "pricing in urban and suburban transport" starts with the words. "I will begin with the proposition that in no other major area are pricing practices so irrational, so out of date, and so conducive to waste as in urban transportation". This quote is almost half a century old, going back to William Vickrey, Nobel Prize Winner in Economics in 1996. Since the publication of Vickrey (1963), road pricing has received much attention in the transportation literature. While the main focus has always been on the reduction of the time costs resulting from congestion, possible environmental benefits have long been noted as a potential positive by-product of road pricing.

In spite of the extensive discussions of the topic that have by no means been restricted to academia, actual applications of the idea are rare. While 
toll roads are quite common in many countries, their main purpose is usually to finance infrastructure. The clearest examples of schemes that are deliberately designed to reduce congestion are the recently introduced London Congestion Charge and the much older Singapore Area Licensing Scheme. Recent highway tolls for trucks in several European countries are also motivated by the joint goals of reducing congestion and pollution, but they are typically not local measures.

In Section 5.1, I review some of the evidence on road pricing. Section 5.2 addresses a related topic: It considers the health effects of collecting tolls electronically, so as to avoid congestion.

\subsection{Experience with Road Pricing}

In line with the overall focus of this survey on ex-post analysis, I will concentrate on the experience with road pricing in London and Singapore, and I will discuss reasons for the apparent failure to adopt such schemes elsewhere. Finally, I will provide a brief account of the impact of the Swiss charge for trucks.

\subsubsection{London}

In 2003, the London Congestion Charge Scheme (LCCS) was introduced in an area of $21 \mathrm{~km}^{2}$ in the City. The charge was initially $£ 5$, but raised to $£ 8$ in 2005. ${ }^{28}$ Santos and Fraser (2006) analyze the early effects of the scheme and simulate the expected effects of the "Western Extension" that was introduced in 2007. They find that the original scheme has been quite effective. They report a decline in the number of cars entering the area by $33 \%$ in the first year of operation, as a result of which the average travel speed increased from 14 to between 16 and 17 kilometers per hour. On the other hand, bus ridership (on inward buses) increased by 37\% between Autumn 2002 and

\footnotetext{
${ }^{28}$ There are exemption rules for specific vehicles.
} 
Autumn 2003, reflecting an increase in the number of buses by $27 \%$ and an increase in passengers per bus of $8 \% .^{29}$

As one might expect, traffic in the vicinity of the area increased, that is $\frac{d T_{2}^{C}}{d \theta}>0$. However, even on the Inner Ring Road, which lies immediately outside the congestion charge area, transportation (vehicles per $\mathrm{km}$ ) only increased by $4 \%$ from 2002 to 2003 , so that these countervailing effects appear to be small.

While there is widespread agreement that the inital London congestion charging scheme reduced road transportation by a substantial amount, the environmental effects are more contentious. Unsurprisingly the combination of reduced automobile transportation and improved traffic flows reduced carbon dioxide emissions (Beevers and Carslaw 2005, Leape 2006). As to the effects on local pollutants, Beevers and Carslaw (2005) find reductions of total emissions of $\mathrm{NO}_{x}$ and PM10 by approximately $12 \%$ in the charging zone, whereas the effects on the Inner Ring Road were small (a 1.5\% increase for PM 10 and a decrease of $1.4 \%$ for $\mathrm{NO}_{X}$ ). They argue that speed increases and reductions in vehicles are equally responsible for the large effects in the charging zone.

Another detailed study of the scheme concludes that it "appears to have modest benefit on air pollution levels and associated life expectancy" (Tonne et al. 2008). The authors of the study simulate the annual average NO2 and PM10 concentrations using an emission-dispersion model. Their calculations suggest that the absolute and relative reductions in concentration within the congestion charging zone were larger than outside the zone. Also, the effects on NO2 concentration were larger than for particulate matters, reflecting the greater share of road transportation of the former pollutants compared to the latter. Finally, the authors translated the predicted pollution reductions into life expectancy gains. They conclude that, per 100'000 population, a total of 188 years of life would be saved within the congestion charge area

\footnotetext{
${ }^{29}$ The authors also report increases in the usage of taxis and bicycles and in pedestrian traffic, whereas truck traffic decreased by $11 \%$.
} 
and 18 years in the rest of Greater London, leading to an overall gain of 1888 years of life.

\subsubsection{Singapore}

Even though the London Congestion Charge has arguably received more attention than any other road pricing scheme, it is not the first of its kind. In 1975, Singapore introduced the Area Licensing Scheme (ALS): Cars entering the Central Business District in the morning rush hour were charged three Singapore dollars per day. The performance in the early years was summarized in a voluminous World Bank report (Watson and Holland 1978), and several authors have dealt with the ALS more recently (e.g., Chin 1996, Christainsen 2006).

The system was highly effective at reducing transport. After the introduction, the number of cars driving into the restricted zone fell by over $45 \%$, resulting in an increase of traffic speed by $22 \%$ (Chin 1996). By 1992, transportation had doubled again, but after almost two decades this is not surprising. In the meantime, in 1989, a similar system had been introduced for the evening rush-hour. It led to a less drastic, but also substantial decline of traffic (by about one third).

The environmental effects of the system appear to be less well understood. Though some efforts were made to monitor the pollution levels around the time of introduction, there appear to be no detailed econometric studies of the effects, so that one has to resort to simple before-and-after comparisons without control for confounding factors. Watson and Holland (1978) report clear decreases in the amount of nitrogen oxides immediately after the introduction of the area licensing scheme, but less clear effects for carbon monoxide. Also, as one would expect, the effects are clearest for the morning peak. All told, although the Singapore Area Licensing Scheme has been evaluated less carefully than the London Congestion Charge, what is known suggests that the experience has been positive. 


\subsubsection{Failed Experiments}

One issue that is striking about road pricing is the rather unusual ratio between academic discussions of the policy and actual implementations. While www.google.scholar.com gives 13400 entries under "road pricing", 30 Santos and Fraser (2006) list only three actual examples of road pricing, namely London, Singapur and a much smaller scheme in Durham. ${ }^{31}$ It is therefore hardly surprising that, among the many authors who have dealt with road pricing, quite a few analyze the political economy question what determines whether road pricing schemes are actually introduced and, if so, whether they move beyond the trial stage. For instance, Ison and Rye (2005) consider test runs in Hong Kong (1983-1985) and Cambridge, U.K. (1990-1993) which did not lead to the successful implementation of road pricing schemes, and they compare the circumstances with those of London. The authors mention several reasons for the lack of enthusiasm in the former two cases. They argue that the congestion problem was not perceived as sufficiently severe in Hongkong and Cambridge, that there was no clear strategic goal of the exercise and that the technology was too complex. Privacy concerns also played a role.

Recent developments have not made it seem very likely that the future of road pricing is bright. A particularly sobering event for the supporters of road pricing was the announcement of London's new mayor Boris Johnson in November 2008 to scrap the newly implemented Western Extension of the London congestion charge region. Even though this plan has not yet been carried out, it is a bad sign for the future of road pricing. Developments in other countries are not very encouraging for the proponents of road pricing either. In Switzerland, for example, though the national government decided in December 2007 to move into the direction of local road pricing experiments, nothing of substance has happened since then. Moreover, the recent political

\footnotetext{
${ }^{30}$ The site was visited on August 14, 2010.

${ }^{31}$ They exclude toll roads where pricing is exclusively motivated by financial considerations (e.g., the much discussed Norwegian toll roads).
} 
climate suggests that the public support for such measures is not particularly strong. Nevertheless Switzerland is one of the few countries where road charges have been used on a large scale to fight transportation externalities; however, the focus was not on inner-city traffic, but on long-distance freight transportation. $^{32}$ Also, some of the impediments to the adoption of road pricing may become less important in the future. For instance, technological improvements are likely to reduce monitoring costs. Also, widespread use of monitoring technologies in other contexts may make road pricing appear comparatively less intrusive. Finally, increasing pressure from growing traffic might make the counter-arguments against road pricing less compelling.

\subsubsection{Freight Transportation Charges}

Since January 1, 2001, trucks driving on Swiss roads have to pay a mileagebased charge (Leistungsabhängige Schwerverkehrsabgabe, LSVA) that depends on weight and on emissions. ${ }^{33}$ Clearly, the reasons for the introduction of this measure differ from those for inner-city road pricing schemes, but at least in the case of Switzerland, local pollution played an important role. The main expected benefit from the scheme was the reduction of pollution on the main transit routes in the Swiss Alps $\left(\frac{d T_{1}^{C}}{d \theta}<0\right)$, but adjustments in the vehicle composition $\left(\frac{d \eta_{1}^{C}}{d \theta}<0\right)$ where also expected. While I am not aware of any academic account of the impact of this large-scale policy measure, a detailed policy report summarizes the effects (ARE 2008).

The policy has succeeded in reducing freight transport in Switzerland or at least containing its growth. In the first two years after the introduction of the LSVA, total heavy freight transportation (in truck kilometers) dropped by $4.8 \%$ and $2.6 \%$, respectively, and it was essentially constant in the three following years. This change reflects both an increasing use of heavier and

\footnotetext{
${ }^{32}$ In the mean time, countries such as Germany, Austria and Slovakia have introduced similar policies.

${ }^{33}$ At the same time, Switzerland agreed to open its roads for trucks with a maximum weight of 34 tons rather than just 28 tons.
} 
more efficient vehicles and a growth of railway transportation.

Moreover, the report suggests that the massive increase in the share of low-emissions vehicles is at least partly the result of the LSVA. ${ }^{34}$ However, in spite of the reduction in transportation and the change in the composition of vehicles, the impact on pollution in the Alpine valleys has reportedly been low. Even though emissions of PM 10 and nitrogen oxides have fallen by $20 \%$ and $14 \%$, respectively, the concentration of these substances has fallen more slowly, and in some locations, it has essentially remained constant. Though the report does not contain an explicit counterfactual, however, it appears likely that "business as usual" would have led to a substantial increase of emissions; at least in the last years before the introduction of the charge, overall transportation was increasing at a rate of more than $3 \%$ per year.

As in the case of other transportation management measures that apply only to fairly small regions, part of the transportation reduction induced by the LSVA probably came at the cost of higher transportation elsewhere $\left(\frac{d T_{2}^{C}}{d \theta}>0\right)$. It has often been argued that trans-alpine freight transportation has moved to Austria instead of Switzerland. Indeed, the number of trailer trucks on one of the main alternative transit routes, the Brenner motorway, has increased dramatically (by more than 30\% between 2001 and 2004). To which extent this reflects substitution from Switzerland to Austria or just the business-as-usual trend is hard to disentangle - at least transportation on the Brenner had already grown by about $40 \%$ between 1994 and $1999 .^{35}$

\subsubsection{Summary and discussion}

Both serious studies and anecdotal evidence show that road pricing can be effective at reducing transportation $\left(\frac{d T_{1}^{C}}{d \theta}<0\right)$ and, if appropriately designed, at reducing specific emissions $\left(\frac{d \eta_{1}^{C}}{d \theta}<0\right)$. Spatial substitution $\left(\frac{d T_{2}^{C}}{d \theta}>0\right)$ is an issue in principle, but seems to be of limited importance at least for the

\footnotetext{
${ }^{34}$ For instance, in the international transit transport, the share of trucks in the category EURO 3 grew from $5 \%$ in 2001 to $72 \%$ in 2005 .

${ }^{35}<$ http: / www.vcoe.at/start.asp?id=4382\&b=92>; visited on April 16, 2010.
} 
case of road pricing in London. In spite of these positive effects, the political support for the measures does not appear solid enough to make a large-scale introduction of road pricing likely in the not too distant future. In some ways, this is a chicken-and-egg problem. Because the evidence for the effects of road pricing is limited to a small number of cases, the arguments for road pricing have to rely mostly on theoretical considerations and simulations. This clearly limits their political appeal.

\subsection{Electronic Toll Pricing}

Sometimes pollution from transportation is reduced by measures that were not primarily designed with this objective. A case in point is the introduction of electronic toll collection (E-ZPass) on highways in the United States. Reducing congestion has the primary purpose of reducing driving time, but it is often claimed to have positive effects on the environment. These effects come from the improved traffic flows, which, in the framework of Section 2, show up as reductions in specific emissions $\eta_{1}^{C}$.

In an interesting paper, Currie and Walker (2009) quantify these effects. The authors start from the observation of engineering studies that electronic toll collection led to $85 \%$ reductions in delays at toll plazas in New Jersey (New Jersey Turnpike Authority). They investigate how this reduced congestion affects the health of infants born to mothers in the vicinity. To this end, they use a difference-in-difference estimation. They compare the change in health of infants within 3 kilometers of a toll plaza before and after the introduction of E-Z pass to the change of health of a control group of infants that live further away, but still within 3 kilometers from a major highway.

The authors identify significant effects of electronic toll collection on infant health. They show that the probability of premature birth was reduced by $7.29 \%$ from the base level of 0.096 , and the probability of low birth weight was reduced by $8.43 \%$ from the base level of 0.083 . 


\subsubsection{Summary and discussion}

The study of Currie and Walker (2009) is not only interesting because it demonstrates the positive health effects of introducing electronic toll collection, but more fundamentally, because it helps to establish that there is a causal relation between traffic pollution and health $\left(\frac{d D_{r}}{d E_{r}}\right)$ at all. While many studies have demonstrated a negative correlation between fetal health of exposure to motor vehicle exhaust, it is not easy to establish a causal effect. The characteristics of pregnant women living near busy highways are likely to be connected to adverse birth outcomes. The careful design of the study by Currie and Walker essentially rules out that the negative relation between traffic exposure and birth outcomes can be explained in such a way. Over the period of observation, the composition of pregnant mothers remains similar both in the treatment and the control group. This lends plausibility to the causal explanation of the observations. This insight is of considerable value beyond the specific case.

The conclusion that improvements of traffic flows may be desirable from an environmental perspective is also potentially of more general interest. However, a full analysis would have to take into account that better traffic flows might also induce further transportation, potentially reducing the beneficial environmental effect.

\section{Conclusions}

This brief review has dealt with evidence on several local transportation policies. Specifically, I focused on public transportation subsidies, road pricing and driving restrictions.

The evidence shows that subsidies for public transport can be effective at reducing automobile transportation $\left(\frac{d T_{1}^{C}}{d \theta}<0\right)$. While this suggests that public transport might help to reduce pollution, the literature that analyzes the direct effects of support for public transport on pollution $\left(\frac{d E_{1}}{d \theta}\right)$ is much smaller. Nevertheless, it seems to transpire that public transport subsidies 
might help to reduce such pollutants as carbon monoxide and nitrogen oxide. There also seem to be positive health effects. Though the net welfare effects are much more contentious, some authors conclude that they might be positive. For this to be the case, however, it is important that the institutions for public transportation are designed optimally. Specifically, the scope for achieving cost reductions by using competitive mechanisms still appears to be large.

Some of the more common applications of driving restrictions, such as pedestrian zones in many medieval European towns, have benefits that are obvious to those that have frequently enjoyed them, but these applications should not primarily be judged by their ability to reduce pollution. In this paper, I have dealt with two specific measures that were designed with the purpose of fighting emissions. In spite of important differences, the "days without cars" in Latin America and the "Low Emission Zones" in Europe have one thing in common: They share the potential for undesired side effects. In the former case, this potential seems to have led to the surprising result that regulation is not only inefficient, but also ineffective (presumably because $\frac{d T_{1}^{C}}{d \theta} \approx 0$ and $\left.\frac{d \eta_{1}^{C}}{d \theta}>0\right)$. In the latter case, the potential problem of spatial substitution $\left(\frac{d E_{2}}{d \theta}>0\right)$ does not materialize. Having said that, however, it remains open whether alternative policies might have done the job more efficiently.

Road pricing also has a large potential for environmental improvements. A large literature shows the existence of a negative (though not very large) elasticity of automobile transportation with respect to own costs. The limited actual experiences with road pricing, in particular, those of Singapore and London, and the attempts to introduce charges for trucks, in particular, in Switzerland, provide further support for the idea that road pricing, properly designed, can affect the overall level of transportation and the modal split, and that it can have desirable effects on local pollution. The problem of spatial diversion exists, but seems larger for long-distance freight transportation with well-defined alternative routes than for local road pricing with less 
substitution opportunities. Perhaps the most important concern with road pricing is the limited acceptance of this instrument, which appears to slow down its introduction.

Even though existing literature has provided many interesting results, it seems that there still is a large potential for further research. Most importantly, it is important to corroborate the results by analyzing the robustness and understanding the determinants of the size of the policy effects more systematically. Most of the studies summarized here deal with specific cases, and it is not always clear what drives the specific results. At least some of the studies, however, could be extended to improve the generalizability of the insights. These studies work with data sets that exploit geographical variation, thus potentially allowing to improve the determinants of the environmental effects of policies more systematically.

In addition, it would seem useful to understand more about the interactions between policy instruments. For instance, road pricing and local transport subsidies are different approaches to dealing with local transport externalities. Can we understand better under which circumstances which instrument is preferable? Or may there be circumstances where both instruments should be used together? Moving beyond the small group of instruments investigated here: How do the local policies investigated here interact with national instruments such as emission norms? For instance, under which circumstances are low emission zones preferable to more general rigid norms for particulate matters or price-based solutions to the problem? The list of topics is long, and it would be interesting to see more empirical research on them.

Quite generally, it appears that the systematic empirical ex-post analysis of actual local transportation policies is still in its infancy. In view of the rich experience that has been made with at least some of these instruments, it would seem important to tap this source of knowledge in order to guide future policy. 


\section{Appendix}

There are several ways to give a microfoundation to the general framework of Section 2. Even though it is also possible to provide a general equilibrium foundation, the following sketch will focus exclusively on the demand effects of the policy under consideration. This appears reasonable for the analysis of local policy effects, for which the main part of the production adjustments may well take part outside the regions under consideration.

Suppose there is a representative household who can consume goods $T_{1}^{C}$, $T_{2}^{C}, T_{1}^{P}, T_{2}^{P}, Y_{1}$ and $Y_{2}$. The utility function $U\left(T_{1}^{C}, T_{2}^{C}, T_{1}^{P}, T_{2}^{P}, Y_{1}, Y_{2} ; \theta\right)$ is assumed to be strictly quasiconcave, twice continuously differentiable and monotone in $\left(T_{1}^{C}, T_{2}^{C}, T_{1}^{P}, T_{2}^{P}, Y_{1}, Y_{2}\right) .{ }^{36}$ The dependence of the utility function on $\theta$ will reflect specifics of the problem. For instance, when $\theta$ corresponds to an increase in the quality of public transportation in region 1 , the marginal rate of substitution $\frac{\partial U / \partial T_{1}^{P}}{\partial U / \partial T_{1}^{C}}$ should be increasing in $\theta$ for any fixed level of the other variables; for other policies (e.g., road pricing) $U$ should be independent of $\theta$.

Suppose further that the household has an exogenously given budget $M$ and faces prices $p_{r}^{C}(\theta)$ and $p_{r}^{P}(\theta)(r=1,2)$. For instance, if the policy corresponds to road pricing in region $r=1, \frac{d p_{1}^{C}}{d \theta}>0$; similarly for fare subsidies, $\frac{d p_{1}^{P}}{d \theta}<0$. Further, a policy might affect specific emissions $\eta_{r}^{C}$ and/or $\eta_{r}^{P}$, without necessarily affecting prices or marginal utility.

Finally, assume the household maximizes utility subject to the budget constraint. The optimal consumption bundle is then determined in the usual way, with a unique optimum given by the condition that marginal rates of substitution between all goods equal the respective price ratios. For each $\theta$, the allocation $\left(T_{1}^{C}, T_{2}^{C}, T_{1}^{P}, T_{2}^{P}, \eta_{1}^{C}, \eta_{2}^{C}, \eta_{1}^{P}, \eta_{2}^{P}, Y_{1}, Y_{2}\right)$ then corresponds to the household optimum $\left(T_{1}^{C}, T_{2}^{C}, T_{1}^{P}, T_{2}^{P}, Y_{1}, Y_{2}\right)$ and the politically determined vector $\left(\eta_{1}^{C}, \eta_{2}^{C}, \eta_{1}^{P}, \eta_{2}^{P}\right)$ of specific emissions.

While counterexamples can easily be found, we shall assume that the

\footnotetext{
${ }^{36}$ We therefore abstract from direct utility effects of specific emissions.
} 
utility function is such that a policy that corresponds to a ceteris paribus increase in $p_{1}^{C}$ leads to a reduction in $T_{1}^{C}$ and an increase in $T_{1}^{P}$. Thus, we are assuming not only that the standard result of consumer theory holds that the compensated own effect of a price increase is negative, we are demanding in addition that car transportation is not a Giffen good. Moreover, we are assuming that car transportation and public transportation within regions are substitutes. Both properties can be guaranteed by choosing utility functions accordingly. As the results reported in Section 3.2.2 show, they are also confirmed empirically.

Moreover, we assume that a policy that leads to an increase in the marginal rate of substitution $\frac{\partial U / \partial T_{1}^{P}}{\partial U / \partial T_{1}^{C}}$ also leads to an increase in public transportation $\left(T_{1}^{P}\right)$ and a reduction in car transportation $\left(T_{1}^{C}\right)$. This would be immediately implied by strict quasiconcavity in the case of two goods; for multiple goods; the result requires further restrictions on utility. ${ }^{37}$

\section{References}

Allianz pro Schiene (2010), "16 Beispiele erfolgreicher Bahnen im Nahverkehr", available at https://www.allianz-pro-schiene.de/publikationen/stadtland-schiene/.

ARE (Bundesamt für Raumentwicklung) 2008, "Volkswirtschaftliche Auswirkungen der LSVA mit höherer Gewichtslimite - Schlussbericht".

Beevers, S.D., and Carslaw, D.C. "The Impact of Congestion Charging on Vehicle Emissions in London", Atmospheric Environment 39, 1-5.

Chin, A.T.H. (1996), "Containing Air Pollution and Traffic Congestion: Transport Policy and the Environment in Singapore", Atmospheric Environment 30, 787-801.

Christainsen, G.B. (2006). "Road Pricing in Singapore after 30 Years", Cato Journal 26, 71-88.

\footnotetext{
${ }^{37}$ Separability restrictions between transportation in different regions and other consumption, while unnecessarily stark, would do the job.
} 
Currie, J., and Walker, R. "Traffic Congestion and Infant Health: Evidence from Z-Pass", NBER Working Paper 15413.

Davis, L.W. (2008). "The Effect of Driving Restrictions on Air Quality in Mexico City", Journal of Political Economy, 116, 38-81.

de Jong, G., and Gunn, H. (2001), "Recent Evidence on Car Cost and Time Elasticities of Travel Demand in Europe", Journal of Transport Economics and Policy, 35, 137-160.

Dodgson, J.S. (1986). "Benefits of Changes in Urban Public Transport Subsidies in the Major Australian Cities." Economic Record, 62: 224-35.

Eskeland, G. S., Feyzioglu, T. (1997). "Rationing Can Backfire: The "Day without a Car" in Mexico City", The World Bank Economic Review, 11 (3), 383-408

EPA (2004): Air Quality Criteria for Particulate Matter (Final Report). U.S.

Environmental Protection Agency, Washington, DC.

Evans, J.H. (2004), "Transit Scheduling and Frequency," Traveler Response to Transportation System Changes, TCRP Report 95, Chapter 9; $<$ http://onlinepubs.trb.org/onlinepubs/tcrp/tcrp_rpt_95c9.pdf>

FitzRoy, F., and Smith, I. (1998). "Public Transport Demand in Freiburg: Why did it Double within a Decade", Transport Policy 5, 163-173.

Glaister, S., and Lewis, D. (1978). "An Integrated Fares Policy for Transport in London." Journal of Public Economics 9,341-55.

Glaister, S. (1984). "The Allocation of Urban Public Transport Subsidy." In J. LeGrand and R. Robinson (eds.), Privatisation and the Welfare State, London: Allen and Unwin, 177-200.

Goh, M. (2002). "Congestion Management and Electronic Road Pricing in Singapore", Journal of Transport Geography, 10, 29-38.

Goodwin, P., Dargay, J., and Hanly, M. (2004), "Elasticities of Road Traffic and Fuel Consumption with Respect to Price and Income: A Review", Transport Reviews, 24, 275-292.

Graham, D.J., and Glaister, S. (2004), "Road Traffic Demand Elasticity: A Review", Transport Reviews, 24, 261-274. 
Graham, D.J., and Glaister, S. (2004), "Road Traffic Demand Elasticity: A Review", Transport Reviews, 24, 261-274.

IFEU (2010), Fortschreibung und Erweiterung 'Daten- und Rechenmodell:

Energieverbrauch und Schadstoffemissionen des motorisierten Verkehrs

in Deutschland 1960-2030 (TREMOD, Version 5)', Heidelberg.

Infras (2010), Handbook of Road Emission Factors, Zürich.

Ison, S., and Rye, T. (2005). "Implementing Road User Charging: The

Lessons Learnt from Hong Kong, Cambridge and Central London", Transport Reviews, 25, 451-465.

Lalive, R., und Schmutzler, A., "Exploring the Effects of Competition for Railway Markets", International Journal of Industrial Organisation, 26, 443-458 (2008)

Lalive, R., und Schmutzler, A., "Auctions vs. Negotiations in Public Procurement - Evidence from Railway Markets", Work in Progress.

Leape, J. (2006). "The London Congestion Charge", Journal of Economic Perspectives, 20 (4), 157-176.

Lüchinger, S., Lalive, R., und Schmutzler, A., "The Effects of Railroad Subsidies on the Environment: Evidence from Germany", Work in Progress

Perry, L., and Wolff, H. (2009): "Air Pollution, Traffic Restrictions and Low Emission Zones, Evidence from Germany", mimeo.

Parry, I.W.H., and Small, K.A. (2009): "Should Urban Transit Subsidies Be Reduced", American Economic Review 99, 700-724.

Pratt, Richard H. (2000), Texas Transportation Institute, Cambridge Systematics, Parsons Brinkerhoff Quade \& Douglas, SG Associates, and McCollom Management Consulting. 2000. Traveler Response to Transportation System Changes: Interim Handbook. Transportation Research Board, Transit Cooperative Research Program Web Document 12 (March).

Pucher, J., and Kurth, S. (1996): "Verkehrsverbund: The Success of Regional Public Transport in Germany, Austria and Switzerland",Transport 
Policy 2, 279-291.

Santos, G., and Fraser, G. (2006), "Road Pricing: Lessons from London" Economic Policy 21, 263-310.

Savage, I. (1997). "Evaluating Transit Subsidies in Chicago." Journal of Public Transportation, 1, 93-117.

Tonne, C., Beevers, S., Armstrong, B., Kelly, F., and Wilkinson, P. (2008), "Congestion Charge: spatial and socioeconomic inequalities" Occupational Environmental Medicine 65 (620-627).

Vickrey, W.S. (1963). "Pricing in Urban and Suburban Transport", American Economic Review Papers and Proceedings, 53 (2), 452-465

Watson, P.L., and Holland, E.P. (1978) "Relieving Traffic Congestion: The Singapore Area Licensing Scheme", World Bank Staff Working Paper No. 281.

Winston, C., and Maheshri, V. (2007) "On the Social Desirability of Urban Rail Systems", Journal of Urban Economics, 62, 362-382.

Winston, C., and Shirley, C. (1998). Alternative Route: Toward Efficient Urban Transportation. Brookings Institution, Washington, DC.

Wolff, H., and Perry, L. (forthcoming): "Trends in Clean Air Legislation in Europe: Particulate Matter and Low Emission Zones." Review of Environmental Economics and Policy. 